\title{
Dental caries in association with viral load in children living with HIV in Phnom Penh, Cambodia: a cross-sectional study
}

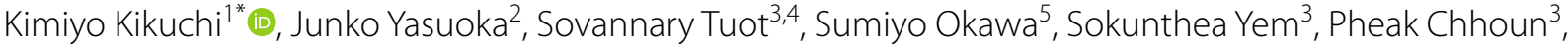 \\ Makoto Murayama ${ }^{6}$, Chantheany Huot ${ }^{7}$ and Siyan $\mathrm{Yi}^{3,8,9,10}$
}

\begin{abstract}
Background: Oral health status is associated with the overall health among people living with human immunodeficiency virus (HIV) infection. However, it is unclear whether dental caries is associated with the viral load in this population. Particularly, dental caries among children living with HIV needs better understanding as this can affect their overall health and future well-being. This study assessed the association between dental caries and viral load among children living with HIV in Phnom Penh, Cambodia.

Methods: This cross-sectional study, conducted at the National Pediatric Hospital as a baseline survey of a randomized controlled trial, included 328, 3-15-year-old children living with HIV and their primary caregivers. Calibrated and trained examiners conducted oral examinations for dental caries (DMFT/dmft index) in the children and retrieved the latest HIV viral load data from the hospital's patient information system. On the dental examination day, the children and their caregivers were invited to answer a questionnaire-based interview. Multiple logistic regression analysis was conducted to assess the association between dental caries and viral load. The cut-off point for undetectable viral load was set at $<40$ copies $/ \mathrm{mL}$.
\end{abstract}

Results: Data from 328 children were included in the analysis; $68.3 \%$ had an undetectable viral load. The mean DMFT/dmft was 7.7 (standard deviation = 5.0). Adjusted regression analysis showed that dental caries in permanent or deciduous teeth was positively associated with detectable viral load (adjusted odds ratio [AOR]: 1.07, 95\% confidence interval [CI]: 1.01-1.14). Conversely, antiretroviral therapy of $\geq 1$ year and self-reported better adherence to antiretroviral drugs were negatively associated with detectable viral load. Among children with detectable viral load, dental caries in permanent or deciduous teeth was positively associated with non-suppression of viral load (>1000 copies/ $\mathrm{mL}$ ) (AOR: 1.12, Cl: 1.03-1.23).

Conclusions: Dental caries was associated with viral load status detection among children living with HIV. This finding suggests that dental caries may affect their immune status. The oral health of children living with HIV should be strengthened, and further research is needed to clarify the causal relationship between viral load and oral health status.

Keywords: Acquired immunodeficiency syndrome, Cambodia, Cross-sectional study, HIV, Dental caries, Viral load

\footnotetext{
*Correspondence: kikuchi.kimiyo.715@m.kyushu-u.ac.jp

1 Department of Health Sciences, Faculty of Medical Sciences, Kyushu

University, Fukuoka, Japan

Full list of author information is available at the end of the article
}

\section{Background}

Globally, acquired immunodeficiency syndrome (AIDS)related deaths decreased by 35\%, from 1.7 million in 2004 (the highest rate) to 1.1 million in 2018 [1]. This change implies that people living with human immunodeficiency 
virus (HIV) now have a longer life expectancy than previously reported [2] and, as a result, the number of people living with HIV is higher than ever [1].

Cambodia is one of the Southeast-Asian countries that has implemented effective HIV prevention and treatment approaches [3]. In 2018, there was a $62 \%$ reduction in new HIV infection cases among the general population of all ages, including children, compared to 2010 [1]. Of all people living with HIV, $81 \%$ received antiretroviral therapy (ART) and 78\% had suppressed viral load in 2018 [1]. However, a high prevalence of dental caries has been reported among uninfected Cambodian children; approximately $93 \%$ of children aged 6 years and $80 \%$ aged 12-13 years had dental caries $[4,5]$. Children living with HIV are no exception to poor oral health, and the condition is even worse than in uninfected children. Thus, these children have a higher number of dental caries than children without HIV infection [6].

The presence of oral lesions indicates HIV progression and an increase in the plasma viral load, which is the amount of HIV in the blood of people living with HIV [7-9]. Among these patients, oral hairy leukoplakia and oral candidiasis are suggested to be associated with a decreased viral load [10, 11]. A HIV-seropositive status could be associated with dental caries due to progressive immunodeficiency [12], influence of medications on salivary flow [13], diet, inadequate oral hygiene, and low socioeconomic status [14]. However, the association between HIV viral load and dental caries remains unclear, especially in the pediatric population. Childhood is a crucial period in which physical development determines the future oral health status and, consequently, may influence overall health.

This study therefore aimed to assess the association between dental caries and viral load among children living with HIV in Phnom Penh, Cambodia.

\section{Methods}

\section{Study design}

This cross-sectional study was conducted from February to April 2018 as a baseline survey of a randomized controlled trial (Clinical Trial Number: ISRCTN15177479) aiming to improve the oral health of children living with HIV at the National Pediatric Hospital, Phnom Penh, Cambodia. Details of the trial have been published elsewhere [15]. This hospital is a tertiary referral facility that provides comprehensive care and treatment for children from across the country, including HIV and dental services, and is a major pediatric HIV clinic in Phnom Penh that provides ART. Children living with HIV receive consultation and collect their medication every 2 months. Dental care is provided free of charge to children living with HIV in this hospital.

\section{Study population}

The target population in this study were children living with HIV and their caregivers. Children who visited the hospital and self-administered their medication were interviewed without the need for their caregivers. The children were included if they were aged 3-15 years on the day of the data collection, had a patient identification number at the study site hospital, and were receiving ART. They were selected from the hospital's ART clinic registry using an age-stratified random sampling method. Randomization was performed using a computerized algorithm by a data analyst who was not a primary member of the research team. The caregivers were eligible only if they were $\geq 18$ years old and were the primary caregiver of the child.

\section{Sample size}

The sample size for the children was calculated based on the number required for the following intervention phase. The sample size set in the study protocol was calculated according to the decayed, missing, or filled permanent teeth (DMFT) score obtained from a previous survey among 8-15-year-old children living with HIV [15]. However, after the completion of the baseline survey among the 3-15-year-old children, we obtained accurate DMFT scores for the study population. Therefore, we revised the sample size based on the following indicators: increment in DMFT, 17\%; baseline DMFT of children living with HIV, 4.0 (standard deviation $[\mathrm{SD}]=3.6$ ); power, $80 \%$; alpha, $5 \%$. The final sample size required was 199 for each group. However, because of the improvement in preventing mother-to-child transmission in Cambodia, the number of children living with HIV aged $<8$ years was low, and we could not recruit the required sample size. Therefore, 160 children were recruited in each group. In this study, both intervention and control groups of children living with HIV were examined, and thus, in total, the required sample size was 320 children.

\section{Data collection}

Two teams, each consisting of one dentist and one dental assistant, collected data on the children's dental caries status. To ensure accuracy of the examination, one of the researchers (a dentist) provided a one-day training session on assessing the dental status of patients using the World Health Organization guidelines [16]. The reproducibility of intra-examiner and inter-examiner evaluations was assessed. The dentists checked for DMFT in 10 children and compared the results between the two groups. The consistency rate of the results was $\geq 0.85$. These data were not included in the main data collected. The total number of DMFT was calculated as the DMFT 
score, and the decayed, missing, or filled deciduous teeth $(\mathrm{dmft})$ score was obtained for deciduous teeth. The overall DMFT and dmft values were evaluated separately and together by the sum of both scores. The severity of dental caries was expressed based on DMFT/dmft $=0$ (no dental caries) and DMFT/dmft $>0$ (the presence of dental caries). If permanent and deciduous teeth were found to occupy the same tooth space, the status of the permanent tooth was recorded according to the World Health Organization guidelines [16]. All dental data were collected in the dental unit of the hospital using disposable mouth mirror.

The research assistants retrieved clinical data from the HIV clinic's registered database, including age, latest viral load within 12 months, ART regimen, and duration of ART. Six research assistants interviewed the caregivers and children on the same day of dental data collection using a structured questionnaire developed based on previously published questionnaires, including the child's adherence to antiretroviral drugs $[17,18]$. They received one-day training from the first author to clarify and improve their understanding of the questionnaire. For the question on adherence, if the drugs were self-administered by the child, we interviewed the child to obtain accurate information. The question was, "How would you rate your/your child's adherence over the past 30 days?" The response choices were very poor, poor, fair, good, very good, or excellent [17].

\section{Statistical analyses}

The data were analyzed descriptively to assess the distribution of the variables. Subsequently, dental caries was classified into dental caries in either the permanent teeth, deciduous teeth, or in all the teeth. We assessed the association of viral load, the dependent variable, with dental caries, age, sex, duration of ART, and adherence to antiretroviral drugs. The age, sex, and duration of ART variables were those included in a model used in a previous study that examined the association between DMFT and CD4+ cell count [12]. The adherence to antiretroviral drugs variable was also included because it is related to viral load in most cases [19]. For all the participants, the independent variables were first examined for association with viral load ("detected" or "undetected"), defined using a cut-off point of $<40$ copies $/ \mathrm{mL}$ according to the detection limit of the tests. We also examined association with viral non-suppression, 1000 copies $/ \mathrm{mL}$, which is the threshold for treatment failure [20] among only those who had a detectable viral load. For bivariate analyses, we used the Chi-square test or Fisher's exact test, if a count in one cell was $<5$, for categorical variables. We used Student's $t$-tests for continuous variables. Further, we applied the multiple logistic regression analysis, and $p<0.05$ was used to indicate statistical significance. All data analyses were performed using IBM SPSS Statistics for Windows, version 24.0 (IBM Corp., Armonk, NY, USA).

\section{Results}

In total, 337 children living with HIV participated in our study. However, data from nine children were excluded owing to missing values. Finally, data from 328 children were included in the analysis. Among the interview responses, 100 were children-only responses while 228 were from both children and caregivers.

\section{General characteristics}

Table 1 shows the characteristics of participating children. Of 328 children, $48.2 \%$ were female. The mean age of the children was 10.8 years (standard deviation $[\mathrm{SD}]=3.0)$. The mean duration of ART was 6.3 years $(\mathrm{SD}=3.6)$. Moreover, $68.3 \%$ of children had an undetectable viral load. Among children with a detectable viral load, the load ranged up to approximately 5,012,000 copies $/ \mathrm{mL}$. Among the participants, $93.0 \%$ had at least one permanent tooth (age range, $6-15$ years old); $57.3 \%$ had at least one deciduous tooth (age range, 3-15 years old). Of them, 50.3\% had both permanent and deciduous teeth (age range, 6-15 years old). The mean values for DMFT and $\mathrm{dmft}$ were $4.0(\mathrm{SD}=3.6)$ and $7.0(\mathrm{SD}=4.9)$, respectively. The mean number of teeth with caries including permanent and deciduous teeth was $7.7(\mathrm{SD}=5.0)$. Only $5.8 \%$ of children were free from caries. For adherence to antiretroviral drugs, no children answered, "very poor." The most frequent response was "good" (51.2\%).

\section{Association between dental caries and detectable viral load}

Table 2 shows the unadjusted and adjusted regression models on the associations between different factors and a detectable viral load. The adjusted analyses indicated that the total DMFT/dmft was positively associated with a detectable viral load (odd ratio [OR]: 1.07, 95\% confidence interval [CI]: 1.02-1.12). Being on ART for $\geq 1$ year (OR: 0.19, 95\% CI: 0.08-0.43) and "excellent" adherence to antiretroviral drugs (OR: 0.24, 95\% CI: 0.08-0.70) were significantly associated with an undetectable viral load.

Adjusted regression analyses were performed in three models stratified by the presence of certain teeth: permanent teeth only, deciduous teeth only, and any teeth. The model that included children with permanent teeth $(\mathrm{n}=305)$ showed that $\geq 1$ year on ART (adjusted OR [AOR]: 0.18, 95\% CI: 0.07-0.45) and "excellent" adherence to antiretroviral drugs (AOR: $0.21,95 \%$ CI: $0.07-$ $0.65)$ were negatively associated with a detectable viral load. The model that included children with deciduous 
Table 1 General characteristics and health status of the study participants

\begin{tabular}{|c|c|c|}
\hline Characteristic & All children $(n=328)$ & $\begin{array}{l}\text { Children with detectable viral load } \\
(\mathrm{n}=104)\end{array}$ \\
\hline \multicolumn{3}{|l|}{ Sex, n (\%) } \\
\hline Female & $158(48.2)$ & $46(44.2)$ \\
\hline Male & $170(51.8)$ & $58(55.8)$ \\
\hline Age (years), mean (SD) & $10.8(3.0)$ & $10.3(3.3)$ \\
\hline $3-5$ & $19(5.8)$ & $9(8.7)$ \\
\hline $6-7$ & $31(9.5)$ & $15(14.4)$ \\
\hline $8-10$ & $78(23.8)$ & $20(19.2)$ \\
\hline $11-12$ & $91(27.7)$ & $27(26.0)$ \\
\hline $13-15$ & $109(33.2)$ & $33(31.7)$ \\
\hline Duration of ART (years), mean (SD) & $6.3(3.6)$ & $4.9(3.7)$ \\
\hline$<1$ & $28(8.5)$ & $19(18.3)$ \\
\hline$\geq 1$ & $300(91.5)$ & $85(81.7)$ \\
\hline \multicolumn{3}{|l|}{ Viral load, n (\%) } \\
\hline Undetected & $224(68.3)$ & - \\
\hline Detected (> 40 copies $/ \mathrm{mL}$ ) & $104(31.7)$ & - \\
\hline \multicolumn{3}{|l|}{ Viral load detected ( $n=104)$ (copies/mL), n (\%) } \\
\hline$<40$ & - & $26(25.0)$ \\
\hline $40-100$ & - & $16(15.4)$ \\
\hline $100-1000$ & - & $12(11.5)$ \\
\hline $1000-10,000$ & - & $12(11.5)$ \\
\hline $10,000-100,000$ & - & $28(26.9)$ \\
\hline$>100,000$ & - & $10(9.6)$ \\
\hline Children without dental caries, n(\%) & $19(5.8)$ & $5(4.8)$ \\
\hline \multicolumn{3}{|l|}{ Dental caries status, n (\%) } \\
\hline $\begin{array}{l}\text { DMFT (total children, } n=305 \text { ) (children with detectable viral load, } \\
n=93 \text { ) }\end{array}$ & $4.0(3.6)$ & $4.2(4.1)$ \\
\hline dmft (total children, $n=188$ ) (children with detectable viral load, $n=68$ ) & $7.0(4.9)$ & $7.8(5.0)$ \\
\hline $\begin{array}{l}\text { DMFT/dmft (total children, } \mathrm{n}=328 \text { ) (children with detectable viral load, } \\
\quad \mathrm{n}=104 \text { ) }\end{array}$ & $7.7(5.0)$ & $8.9(5.3)$ \\
\hline \multicolumn{3}{|l|}{ Adherence to antiretroviral drugs in the past 30 days, $\mathrm{n}(\%)$} \\
\hline Very poor & $0(0.0)$ & $0(0.0)$ \\
\hline Poor & $3(0.9)$ & $3(2.9)$ \\
\hline Fair & $25(7.6)$ & $9(8.7)$ \\
\hline Good & $168(51.2)$ & 54 (51.9) \\
\hline Very good & 75 (22.9) & $28(26.9)$ \\
\hline Excellent & $52(15.9)$ & $8(7.7)$ \\
\hline Unknown & $5(1.5)$ & $2(2.0)$ \\
\hline
\end{tabular}

SD standard deviation, ART antiretroviral therapy, DMFT decayed, missing, or filled permanent teeth, dmft decayed, missing, or filled deciduous teeth

teeth $(\mathrm{n}=188)$ showed that $\mathrm{dmft}$ was positively associated with detectable viral load (AOR: 1.10, 95\% CI: 1.01-1.19). At least 1 year on ART (AOR: 0.19, 95\% CI: 0.07-0.57) while "excellent" adherence to antiretroviral drugs (AOR: 0.21, 95\% CI: 0.04-0.97) were negatively associated with detectable viral load. The model that included children with all types of teeth $(n=328)$ showed that total DMFT/dmft was positively associated with a detectable viral load (AOR: 1.07, 95\% CI: 1.01-1.14), and that $\geq 1$ year on ART (AOR: 0.22, 95\% CI: 0.09-0.52) and "excellent" adherence to antiretroviral drugs (AOR: 0.16, 95\% CI: 0.05-0.51) were negatively associated with a detectable viral load.

\section{Association between dental caries and viral non- suppression}

Table 3 shows the association between dental caries and viral non-suppression (>1000 copies/mL). Unadjusted 
Table 2 Association between dental caries and viral detection (> 40 copies $/ \mathrm{mL}$ )

\begin{tabular}{|c|c|c|c|c|c|c|c|c|c|c|c|c|}
\hline \multirow[t]{3}{*}{ Variable } & \multirow{2}{*}{\multicolumn{3}{|c|}{ Unadjested analysis $^{a}$}} & \multicolumn{9}{|c|}{ Adjusted analysis } \\
\hline & & & & \multicolumn{3}{|c|}{$\begin{array}{l}\text { Viral non-suppression status } \\
\text { among children who had } \\
\text { permanent teeth }(n=305)\end{array}$} & \multicolumn{3}{|c|}{$\begin{array}{l}\text { Viral non-suppression status } \\
\text { among children who had } \\
\text { deciduous teeth }(n=188)\end{array}$} & \multicolumn{3}{|c|}{$\begin{array}{l}\text { Viral non-suppression status } \\
\text { among all children }(n=328)\end{array}$} \\
\hline & $\begin{array}{l}\text { Unadjusted } \\
\mathrm{OR}^{\mathrm{b}}\end{array}$ & \multicolumn{2}{|c|}{$95 \% \mathrm{Cl}^{\mathrm{C}}$} & Adjusted OR & \multicolumn{2}{|c|}{$95 \% \mathrm{Cl}$} & Adjusted OR & \multicolumn{2}{|c|}{$95 \% \mathrm{Cl}$} & Adjusted OR & \multicolumn{2}{|c|}{$95 \% \mathrm{Cl}$} \\
\hline \multicolumn{13}{|c|}{ Dental caries status } \\
\hline $\mathrm{DMFT}^{\mathrm{d}}$ & 1.02 & 0.96 & 1.10 & 1.02 & 0.94 & 1.10 & - & - & - & - & - & - \\
\hline $\mathrm{dmft}^{\mathrm{e}}$ & 1.06 & 0.99 & 1.12 & - & - & - & 1.10 & 1.01 & $1.19^{*}$ & - & - & - \\
\hline DMFT/dmft & 1.07 & 1.02 & $1.12^{* *}$ & - & - & - & - & - & - & 1.07 & 1.01 & $1.14^{*}$ \\
\hline \multicolumn{13}{|l|}{ Sex } \\
\hline Female & Ref. & - & - & Ref. & - & - & Ref. & - & - & Ref. & - & - \\
\hline Male & 1.26 & 0.79 & 2.01 & 1.35 & 0.80 & 2.37 & 1.67 & 0.86 & 3.24 & 1.39 & 0.84 & 2.29 \\
\hline \multicolumn{13}{|l|}{ Age $(\text { years })^{f}$} \\
\hline $3-10$ & Ref. & - & - & Ref. & - & - & Ref. & - & - & Ref. & - & - \\
\hline $11-15$ & 0.80 & 0.50 & 1.29 & 0.91 & 0.49 & 1.66 & 2.11 & 0.94 & 4.77 & 1.03 & 0.59 & 1.82 \\
\hline \multicolumn{13}{|c|}{ Duration of $\mathrm{ART}^{\mathrm{g}}{\text { (years })^{\mathrm{h}}}^{\mathrm{h}}$} \\
\hline$<1$ & Ref. & - & - & Ref. & - & - & Ref. & - & - & Ref. & - & - \\
\hline$\geq 1$ & 0.19 & 0.08 & $0.43^{* *}$ & 0.18 & 0.07 & $0.45^{* *}$ & 0.19 & 0.07 & $0.57^{* *}$ & 0.22 & 0.09 & $0.52^{*}$ \\
\hline \multicolumn{13}{|c|}{ Adherence to antiretroviral drugs in the past 30 days } \\
\hline Poor/fair & Ref. & - & - & Ref. & - & - & Ref. & - & - & Ref. & - & - \\
\hline Good & 0.63 & 0.28 & 1.43 & 0.51 & 0.22 & 1.18 & 0.79 & 0.21 & 3.02 & 0.56 & 0.24 & 1.31 \\
\hline Very good & 0.79 & 0.33 & 1.92 & 0.64 & 0.26 & 1.61 & 0.83 & 0.20 & 3.43 & 0.63 & 0.25 & 1.58 \\
\hline Excellent & 0.24 & 0.08 & $0.70^{*}$ & 0.21 & 0.07 & $0.65^{* *}$ & 0.21 & 0.04 & $0.97^{*}$ & 0.16 & 0.05 & $0.51^{* *}$ \\
\hline \multicolumn{13}{|c|}{ a Viral load was a binary variable (detected or undetected) } \\
\hline \multicolumn{13}{|c|}{ b OR, odds ratio } \\
\hline \multicolumn{13}{|c|}{${ }^{\mathrm{C}} \mathrm{Cl}$, confidence interval } \\
\hline \multicolumn{13}{|c|}{ d DMFT, decayed, missing, or filled permanent teeth } \\
\hline \multicolumn{13}{|c|}{ e dmft, decayed, missing, or filled deciduous teeth } \\
\hline \multicolumn{13}{|c|}{ f The cut-off was set as 10 years old (median of mixed dentition) } \\
\hline \multicolumn{13}{|c|}{${ }^{g}$ ART, antiretroviral therapy } \\
\hline h The cut-off wa & $\mathrm{s}$ set as 1-year $(\mathrm{mc}$ & st likely & riod atta & ining viral RNA th & olds & 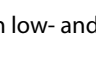 & iddl income & tries & & & & \\
\hline${ }^{*} p<0.05 ;{ }^{* *} p<0$ & & & & & & & & & & & & \\
\hline
\end{tabular}

analyses showed that dmft (OR: 1.12, 95\% CI: 1.01-1.25) and total DMFT/dmft (OR: 1.10, 95\% CI: 1.02-1.19) were positively associated with viral non-suppression.

Among children with a detectable viral load who had deciduous teeth $(\mathrm{n}=68)$, dmft was positively associated with viral non-suppression (AOR: 1.22, 95\% CI: 1.051.41). Among all the children with a detectable viral load $(\mathrm{n}=104)$, the analyses indicated that total DMFT/dmft was positively associated with viral non-suppression (AOR: 1.12, 95\% CI: 1.03-1.23).

\section{Discussion}

In this study, we found that dental caries, duration of ART, and adherence to antiretroviral drugs were associated with viral load. To the best of our knowledge, this is the first study to reveal the association between dental caries and viral load among children living with HIV.
The undetectable viral load rate of $68.3 \%$ in our study was similar to that reported in previous studies [21, 22]. In an intervention study that aimed to examine the effectiveness of ART among Cambodian children living with HIV, the undetectable viral load rate was $81 \%$ [22]. A meta-analysis that included seven studies on children living with HIV from 2010, later estimated the undetectable viral load rate $(<40$ copies $/ \mathrm{mL})$ as $72.7 \%$ (95\% CI: $62.6-$ 82.8) after 6 months on first-line ART [21].

In our study, the high occurrence of dental caries in permanent or deciduous teeth was associated with a detectable viral load. Furthermore, a high number of dental caries in permanent or deciduous teeth was associated with viral non-suppression. However, this finding contrasted with a study in the United States conducted by Moscicki et al. [23] who found no association between viral load and oral health indicators 
Table 3 Association between dental caries and viral non-suppression (> 1000 copies $/ \mathrm{mL}$ )

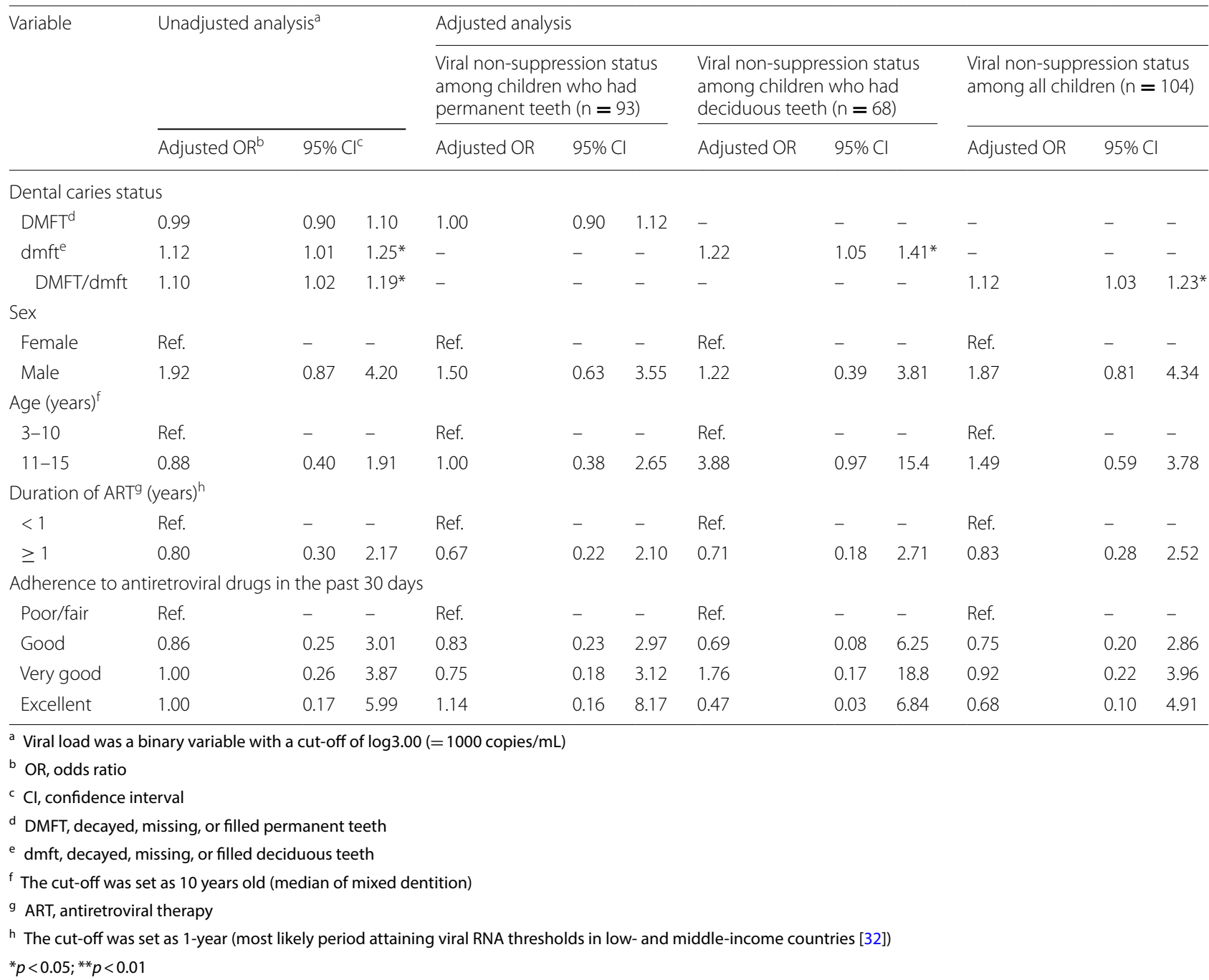

among children and adolescents aged 7-16 years. However, most of the participants in that study had permanent teeth, and their results do not completely contradict those from our study. We also did not find an association when we included only children with permanent teeth. However, the reason for the lack of this association is unclear. To address this, children's immature immunological status or the dental risk factors during development will have to be studied. For adults living with HIV, some studies suggested an association between dental caries and advanced viral load. In a study in the United States, Baqui et al. [7] demonstrated that the majority of adults with HIV with a high viral load had a DMFT score $>20$. However, the correlation was not significant. Some studies, including our previous study that focused only on children 8-15-year-old, demonstrated a positive association between dental caries and CD4 + cell count among children living with
HIV [12, 24]. This may suggest a correlation between dental caries and viral load, as CD4 + cell count has a negative correlation with viral load. With respect to the association between viral load and dental caries, people living with HIV in the advanced stages of AIDS experience xerostomia. It is often diagnosed due to a lack of salivary flow among people living with HIV in the advanced stages of immunosuppression [25]. The lack of salivary flow could be one of the causes of dental caries [25, 26]. However, the causal relationship is not clear, and the influence of poor oral health status on AIDS-related diseases cannot be ruled out based on our results. Alternatively, the compromised systemic health of children may be a factor associated with low immune status, higher viral load, and poor oral health, although further study is needed to clarify the mechanism. However, considering the association between general health and oral health status, more efforts and 
resources need to be directed toward education and clinical care of children's teeth.

Our study also demonstrates that other factors, such as duration of ART and adherence to antiretroviral drugs, were associated with viral load. Similar to our research, longer duration on ART and high adherence to antiretroviral drugs were found to be associated with viral suppression or lower viral load in different studies [21, $27-30]$. This association implies the effectiveness of ART in improving the immune system. In many cases, the selfreported adherence rate is often biased due to improper recalling and social desirability [31]. However, the positive association identified in our study may suggest that participants' responses are close to reality.

This study has some limitations. A cross-sectional design was employed, and there was no control group. Therefore, this study does not prove causality. We assessed the presence of dental caries and need further studies to assess other dental risk factors. In addition, as the data were collected from only one hospital, it may not be generalizable. However, our study site hospital includes the largest number of children living with HIV in the country and is the main referral hospital for children living with HIV in Phnom Penh. Thus, our study findings are applicable to the general population of children living with HIV in Cambodia.

\section{Conclusions}

In conclusion, this study revealed a significant association between HIV viral load and dental caries among children living with HIV in Phnom Penh. Thus, the oral health status might have affected the disease progression, as well as the immune status of the children. Further research is needed to clarify the causal relationship between viral load and the oral health status.

\section{Abbreviations \\ AIDS: acquired immunodeficiency syndrome; AOR: Adjusted OR; ART: Antiret- roviral therapy; DMFT: Decayed, missing, or filled permanent teeth; dmft: Decayed, missing, or filled deciduous teeth; HIV: Human immunodeficiency virus; OR: Odds ratio; SD: Standard deviation.}

\section{Acknowledgements}

The authors thank the staff at the National Pediatric Hospital, Phnom Penh, Cambodia and the research staff for their contributions to this study. This research was supported by JSPS KAKENHI Grant Number JP17H04658.

\section{Authors' contributions}

Conceptualization: KK, JY, MM, ST, and SY. Data curation: ST, SY, and PC. Formal analysis: KK. Funding acquisition: KK. Investigation: ST, PC, CH, and SY. Methodology: KK. Project administration: ST. Supervision: MM, SY. Writing—original draft: KK. Writing —review and editing: JY, MM, ST, SO, CH, and SY. All authors read and approved the final manuscript.

\section{Funding}

The content is solely the responsibility of the authors and does not necessarily represent the official views of the funder.

\section{Availability of data and materials}

The datasets used and/or analyzed during the current study are available from the corresponding author on reasonable request.

\section{Ethics approval and consent to participate}

Ethics approval was obtained from the National Ethics Committee for Health Research, Ministry of Health, Cambodia (approval number: 289NECHR) and the Research Ethics Committee of Kyushu University, Fukuoka, Japan (approval number: 29067). Written informed consent was obtained from the caregivers before data collection and assent to participate in the study was obtained from the children. Participation was voluntary and confidentiality was maintained.

\section{Consent for publication}

Not applicable.

\section{Competing interests}

The authors declare that they have no competing interests.

\section{Author details \\ ${ }^{1}$ Department of Health Sciences, Faculty of Medical Sciences, Kyushu Univer- sity, Fukuoka, Japan. ${ }^{2}$ Research and Education Center for Prevention of Global Infectious Diseases of Animals, Tokyo University of Agriculture and Technology, Tokyo, Japan. ${ }^{3}$ KHANA Center for Population Health Research, Phnom Penh, Cambodia. ${ }^{4}$ Department of Community and Global Health, Graduate School of Medicine, The University of Tokyo, Tokyo, Japan. ${ }^{5}$ Cancer Control Center, Osaka International Cancer Institute, Osaka, Japan. ${ }^{6}$ Kawasaki City Dentists Association, Kanagawa, Japan. ${ }^{7}$ National Paediatric Hospital, Phnom Penh, Cambodia. ${ }^{8}$ Center for Global Health Research, Touro University California, Vallejo, CA, USA. ${ }^{9}$ Saw Swee Hock School of Public Health, National University of Singapore and National University Health System, Singapore, Singapore. ${ }^{10}$ School of Public Health, National Institute of Public Health, Phnom Penh, Cambodia.}

Received: 14 June 2020 Accepted: 14 February 2021

Published online: 25 March 2021

\section{References}

1. UNAIDS. AIDSinfo. Geneva: UNAIDS; 2019 [cited 2019 Augst 12]. http:// aidsinfo.unaids.org/.

2. Antiretroviral Therapy Cohort C. Survival of HIV-positive patients starting antiretroviral therapy between 1996 and 2013: a collaborative analysis of cohort studies. Lancet HIV. 2017;4(8):e349-e56.

3. WHO South-East Asia Region. Are key populations really the "KEY" to ending AIDS in Asia? Putting Asia's HIV response back on track. New Delhi: WHO South-East Asia Region; 2018.

4. Turton B, Chher T, Sabbah W, Durward C, Hak S, Lailou A. Epidemiological survey of early childhood caries in Cambodia. BMC Oral Health. 2019;19(1):107.

5. Chher T, Turton B, Hak S, Beltran E, Courtel F, Durward C. Dental caries experience in Cambodia: findings from the 2011 Cambodia National Oral Health Survey. J Int Oral Health. 2016;8(1):1-7.

6. Kikuchi K, Furukawa Y, Tout S, Pal K, Huot C, Yi S. "Who cares" is key: factors associated with oral health status in children living with HIV in Phnom Penh,\&nbsp;Cambodia. AIDS Care. 2019;32:1-9.

7. Baqui A, Meiller T, Jabra-Rizk M, Zhang M, Kelley J, Falkler W. Association of HIV viral load with oral diseases. Oral Dis. 1999;5(4):294-8.

8. Duggal MS, Abudiak H, Dunn C, Tong HJ, Munyombwe T. Effect of CD4 + lymphocyte count, viral load, and duration of taking anti-retroviral treatment on presence of oral lesions in a sample of South African children with HIV+/AIDS. Eur Arch Paediatr Dent. 2010;11(5):242-6.

9. Ramos-Gomez FJ, Folayan MO. Oral health considerations in HIV-infected children. Curr HIV/AIDS Rep. 2013;10(3):283-93.

10. Hodgson TA, Greenspan D, Greenspan JS. Oral lesions of HIV disease and HAART in industrialized countries. Adv Dent Res. 2006;19(1):57-62.

11. Greenspan D, Komaroff E, Redford M, Phelan JA, Navazesh M, Alves ME, et al. Oral mucosal lesions and HIV viral load in the Women's Interagency HIV Study (WIHS). J Acquir Immune Defic Syndr. 2000;25(1):44-50. 
12. Kikuchi K, Furukawa Y, Tuot S, Pal K, Huot C, Yi S. Association of oral health status with the CD4 + cell count in children living with HIV in Phnom Penh, Cambodia. Sci Rep. 2019;9(1):14610.

13. Subramaniam P, Kumar K. Cariogenic potential of medications used in treatment of children with HIV infection. Spec Care Dentist. 2014;34(3):127-30.

14. Oliveira CA, Tannure PN, de Souza IPR, Maia LC, Portela MB, Castro GF. Is dental caries experience increased in HIV-infected children and adolescents? A meta-analysis. Acta Odontol Scand. 2015;73:481-7.

15. Kikuchi K, Yasuoka J, Tuot S, Yem S, Chhoun P, Okawa S, et al. Improving overall health of children living with HIV through an oral health intervention in Cambodia: study protocol for a randomized controlled trial. Trials. 2018;19(1):673.

16. WH Organization. Oral health surveys: basic methods. 5th ed. Geneva: World Health Organization; 2013.

17. Chaiyachati K, Hirschhorn LR, Tanser F, Newell ML, Barnighausen T. Validating five questions of antiretroviral nonadherence in a publicsector treatment program in rural South Africa. AIDS Patient Care STDS. 2011;25(3):163-70.

18. WHO. Oral health survey: basic methods. 5th ed. Geneva: WHO; 2013

19. WHO. Consolidated guidelines on the use of antiretroviral drugs for treating and preventing HIV infection: recommendation for a public health approach. Geneva:WHO; 2016.

20. WHO. What's new in treatment monitoring: viral load and CD4 testing. Geneva: WHO; 2017

21. Boerma RS, Boender TS, Bussink AP, Calis JC, Bertagnolio S, Rinke de Wit TF, et al. Suboptimal viral suppression rates among HIV-infected children in low- and middle-income countries: a meta-analysis. Clin Infect Dis. 2016:63(12):1645-54

22. Janssens B, Raleigh B, Soeung S, Akao K, Te V, Gupta J, et al. Effectiveness of highly active antiretroviral therapy in HIV-positive children: evaluation at 12 months in a routine program in Cambodia. Pediatrics. 2007;120(5):e1134-40.

23. Moscicki AB, Yao TJ, Ryder MI, Russell JS, Dominy SS, Patel K, et al. The burden of oral disease among perinatally HIV-infected and HIV-exposed uninfected youth. PLoS ONE. 2016;11(6):e0156459.
24. Hicks MJ, Flaitz CM, Carter AB, Cron SG, Rossmann SN, Simon CL, et al. Dental caries in HIV-infected children: a longitudinal study. Pediatr Dent. 2000;22(5):359-64

25. Valdez IH, Pizzo PA, Atkinson JC. Oral health of pediatric AIDS patients: a hospital-based study. ASDC J Dent Child. 1994;61(2):114-8.

26. Kho HS, Lee SW, Chung SC, Kim YK. Oral manifestations and salivary flow rate, $\mathrm{pH}$, and buffer capacity in patients with end-stage renal disease undergoing hemodialysis. Oral Surg Oral Med Oral Pathol Oral Radiol Endod. 1999:88(3):316-9.

27. Ciaranello AL, Chang Y, Margulis AV, Bernstein A, Bassett IV, Losina $E$, et al. Effectiveness of pediatric antiretroviral therapy in resourcelimited settings: a systematic review and meta-analysis. Clin Infect Dis. 2009;49(12):1915-27.

28. O'Connor J, Smith C, Lampe FC, Johnson MA, Chadwick DR, Nelson M, et al. Durability of viral suppression with first-line antiretroviral therapy in patients with HIV in the UK: an observational cohort study. Lancet HIV. 2017:4(7):e295-302

29. Sutcliffe CG, van Dijk JH, Bolton C, Persaud D, Moss WJ. Effectiveness of antiretroviral therapy among HIV-infected children in sub-Saharan Africa. Lancet Infect Dis. 2008:8(8):477-89.

30. Dziva Chikwari C, Ferrand RA, Simms V. Association between self-reported adherence and HIV viral load suppression among older children and adolescents. J Acquir Immune Defic Syndr. 2017;76(3):e87-9.

31. Nieuwkerk PT, Oort FJ. Self-reported adherence to antiretroviral therapy for HIV-1\&nbsp;infection and virologic treatment response: a meta-analysis. J Acquir Immune Defic Syndr. 2005;38(4):445-8.

32. McMahon JH, Elliott JH, Bertagnolio S, Kubiak R, Jordan MR. Viral suppression after 12 months of antiretroviral therapy in low- and middle-income countries: a systematic review. Bull World Health Organ. 2013;91(5):377-85E

\section{Publisher's note}

Springer Nature remains neutral with regard to jurisdictional claims in published maps and institutional affiliations.
Ready to submit your research? Choose BMC and benefit from:

- fast, convenient online submission

- thorough peer review by experienced researchers in your field

- rapid publication on acceptance

- support for research data, including large and complex data types

- gold Open Access which fosters wider collaboration and increased citations

- maximum visibility for your research: over $100 \mathrm{M}$ website views per year

At $\mathrm{BMC}$, research is always in progress.

Learn more biomedcentral.com/submissions 